\title{
Influencing factors in choosing delivery method: Iranian primiparous women's perspective
}

\author{
Ahmad Moosavi ${ }^{1}$, Sepideh Gareh Sheikhlou ${ }^{2}$, Sara Gareh Sheikhlou ${ }^{3}$, Kolsum Abdolahi ${ }^{4}$, Leila Yaminifar ${ }^{5}$, \\ Maryam Maktabi ${ }^{5}$
}

${ }^{1}$ Department of Health and Community Medicine, Dezful University of Medical Sciences, Dezful, Iran

${ }^{2}$ Department of Obstetrics and Gynecology, Dezful University of Medical Sciences, Dezful, Iran

${ }^{3}$ Iran University of Medical Sciences, Tehran, Iran

${ }^{4}$ Obstetrician and Gynecologist, Iran

${ }^{5}$ Department of Obstetrics and Gynecology, Arak University of Medical Sciences, Arak, Iran

Type of article: Original

\begin{abstract}
Background: Studies on the primiparous mothers' decision on delivery method are limited.

Aim: The aim of his study was to determine the factors that influence the choice of delivery method by Iranian primiparous women.

Methods: This cross-sectional study was conducted in April through September 2014. Participants were 460 primiparous women in 8 hospitals of 4 cities in Iran. Finally, 230 cesarean section and 230 vaginal delivery women were selected. Inclusion criteria were being primiparous, and having no contraindication for vaginal delivery. Study tool was a researcher-developed questionnaire that its validity and reliability were proved. Data were gathered by direct interview and analyzed by SPSS version 16 .

Results: Average age of the participants was 23 years. Factors that correlated with the choice of Cesarean section were upper education, high socioeconomic level, tendency of husband, living with the husband's family, insistence of the physician, receiving maternal care in personal offices, fear of delivery pain, low knowledge of the mother, high age of marriage and pregnancy, history of abortion, and lack of family support. More than $60 \%$ of the participants had little knowledge about the delivery methods. Satisfaction with cesarean section was $70 \%$ and with the vaginal delivery was $77 \%$. Half of the cesareans were performed on the insistence of the physician. Conclusion: Considering the factors identified in this study, can enforce the intention of mothers to have vaginal delivery by improving their knowledge and perception about this delivery method.

Keywords: Primiparous Women, Cesarean Section, Vaginal Delivery, Influencing Factors
\end{abstract}

\section{Introduction}

Birth-giving is a blessing that makes the proliferation of humans possible. The mechanism of birth-giving is an automatic process with no need for intervention $(1,2)$. The process nowadays is performed in two methods of vaginal delivery and cesarean section (3). Although the vaginal (natural) delivery is known as the best delivery method, the rate of cesarean section has been increased considerably in recent years (4). Cesarean section is a delivery method in which the child is brought out through a cut in the abdomen (5). Numerous studies have shown the high rate of C-section around the world. The rate was $22 \%$ in the USA (6), 25\% in Brazil, $27 \%$ in Chile, and 17 $40 \%$ in 19 countries of Latin America (7). While the World Health Organization (WHO) recommends that the rate must not exceed $15 \%$ of all births (8). The C-section rate is also high in Iran (9-11). On the other hand, consequences such as death, infection, long hospital stay, heavy costs, and damage to newborns are more probable in C-section (12-14). Lack of proper knowledge of C-section and having misinformation about vaginal delivery are reported as the main factors that cause mothers to engage in C-section $(15,16)$. Fear, stress and pain are other factors that affect the choice of mothers (17). Previous studies have shown that the experience of mothers from their previous birth-giving has a determinant role in choosing the delivery method (18). Yet the studies on the

\section{Corresponding author:}

Sepideh Gareh Sheikhlou, Department of Obstetrics and Gynecology, Dezful University of Medical Sciences, Dezful, Iran. Tel.: +98.9385889860, Email: dr_ahmad_mosavi@yahoo.com

Received: January 30, 2016, Accepted: February 05, 2017, Published: April 2017

iThenticate screening: January 02, 2017, English editing: March 12, 2017, Quality control: April 10, 2017

(C) 2017 The Authors. This is an open access article under the terms of the Creative Commons Attribution-NonCommercialNoDerivs License, which permits use and distribution in any medium, provided the original work is properly cited, the use is non-commercial and no modifications or adaptations are made. 
primiparous mothers' decision on delivery method are limited and despite the importance of these deliveries, only a few studies have been performed in this regard. Therefore, this study has been conducted with the aim of determining the influencing factors on choosing the delivery method among Iranian primiparous women.

\section{Material and Methods}

This cross-sectional study was conducted in April through September 2014. The study population was primiparous women who were hospitalized in 8 hospitals of 4 cities in Iran (Tehran, Tabriz, Ardabil, and Urmia) for birth giving. Using the Cochrane formula and assuming 1 million annual primiparous births, the sample size was calculated as 384 individuals. To consider the unresponsive samples and for increasing the power of the study, the calculated sample size received a $20 \%$ addition. Then the final sample size was considered as 460 of which half of them (230 people) were selected from C-section women and the other half (230 people) from the vaginal delivery group. The participants were selected by the convenient sampling method from 8 hospitals of 4 cities of Iran. The reason for choosing primiparous women was that having $\mathrm{C}$-section in the first delivery is an indication for $\mathrm{C}$-section in the next deliveries, and refusing to have it in the next delivery may result in harm to the mother. Then, primiparous women have more freedom in choosing the delivery method. To reduce the effect of confounding factors, the inclusion criterion was set as having no contra-indication for vaginal delivery. The data collection tool was a researcherdeveloped questionnaire that its validity was assessed against the opinions of 10 experts and its reliability was examined using a pilot study with 30 participants $(\alpha=0.8)$. The questionnaires were completed through interview. Variables of interest were some demographic characteristics of the mother and her husband, the reason for choosing the delivery method, received maternal care, history of abortion (intentional and un-intentional), the knowledge of the mother about the advantages and disadvantages of delivery methods, and the satisfaction of the husband. Before conducting the interviews, the informed consent of the participants was obtained along with the permission of the hospital officers. To examine the knowledge of the mothers about the delivery methods, we used a 4-degree Likert scale including: 1. has no information; 2. has little information (can describe the differences of the two methods); 3. Has some information (can describe the advantages and disadvantages of the methods), 4. Has complete information (in addition to previous ones, can describe the care that she will need after the procedure). The data analysis was done using the Statistical Package for Social Sciences (SPSS) software version 16.

\section{Results}

Most of the participants (65.5\%) were in the age group 17-23 years old and the age group 34-38 comprised only $1.1 \%$ of the study participants. The average age of studied women was 23 years and $77.7 \%$ of them were housewives. The majority of them were high school graduates and the average income of them (or their family) was 4 million IR Rials (approximately equals to 120 US Dollar). Table 1 shows the demographic characteristics of the study participants. Of the husbands of those women who had vaginal delivery, the proportion of husbands that were satisfied with the delivery method was equal to the proportion of husbands that were neutral with it. The proportion of dis-satisfied husbands was not considerable. Of the husbands of women who had C-section the biggest proportion belonged to the satisfied group and the lowest proportion belonged to the dis-satisfied group. The most stated reason for having $\mathrm{C}$-section was insistence of the physician and for having vaginal delivery was recommendation by the family/friends. Yet the physicians had an important role in choosing the delivery method in those who had vaginal delivery. Having no information about the delivery method had the lowest proportion in women of both delivery methods. On the knowledge of the primiparous women about the delivery method, for both the C-section and vaginal delivery, the biggest proportion belonged to the group that had little information and could only describe the differences of the two methods. And the lowest proportion belonged to those women who had complete information in this regard and in addition to the process, could describe the routine care after each way of delivery. Yet the proportion of the participants that had complete information was bigger in those women who had vaginal delivery. Overall, the number of satisfied primiparous women in both delivery methods was bigger than those who were dissatisfied. Yet, Figure1 indicates that the participants were more satisfied with vaginal delivery. The majority of primiparous women who had C-section had received maternal care during pregnancy from private physicians. While those women who had vaginal delivery had received care from private physicians, physicians of the public sector, and health homes to almost the same proportion. The maternal care by midwives had the smallest proportion in both of the delivery methods. The most important advantages and disadvantages of each delivery method from the perspective of Iranian primiparous women are presented in Table 2. While less pain is stated as the most important advantage of $\mathrm{C}$-section, the participants stated the safety and fast recovery as the most important advantages of vaginal delivery. The most important disadvantage of $\mathrm{C}$-section from the perspective of the participants were the side effects of the anesthesia and delayed recovery, and of the vaginal delivery, was the severe pain during the delivery. 
http://www.ephysician.ir

Table1. Demographic characteristics of the Iranian primiparous women $(\mathrm{N}=460)$

\begin{tabular}{|l|l|l|l|}
\hline Variable & Level & Cesarean section & Vaginal delivery \\
\hline Employment & Employed & 15.5 & 16.6 \\
\cline { 2 - 4 } & Housewife & 84.5 & 83.4 \\
\hline \multirow{5}{*}{ Mother's education } & Illiterate & 5.5 & 6.66 \\
\cline { 2 - 4 } & Literate & 34.4 & 44.4 \\
\cline { 2 - 4 } & High school & 42.2 & 32.22 \\
\cline { 2 - 4 } & University & 17.7 & 16.66 \\
\hline Husband's education & Illiterate & 10 & 11.11 \\
\cline { 2 - 4 } & Literate & 37.7 & 28.8 \\
\cline { 2 - 4 } & High school & 25.5 & 33.33 \\
\cline { 2 - 4 } & University & 26.6 & 26.6 \\
\hline Hother's birth place & Rural & 85.55 & 87.77 \\
\cline { 2 - 4 } & Urban & 14.44 & 12.22 \\
\hline \multirow{2}{*}{ Living Place } & Rural & 83.33 & 85.55 \\
\cline { 2 - 4 } & Urban & 16.66 & 14.45 \\
\hline Income (million IR Rials) & Rural & 81.11 & 85.55 \\
\cline { 2 - 4 } & Urban & 18.88 & 14.45 \\
\cline { 2 - 4 } & 3 or less & 24.44 & 31.11 \\
\cline { 2 - 4 } & to 5 & 35.55 & 35.55 \\
\hline & 5 to 7 & 25.55 & 22.22 \\
\hline & 7 to 10 & 8.88 & 3.33 \\
\cline { 2 - 4 } & More than 10 & 5.55 & \\
\hline
\end{tabular}

Table 2. Advantages and disadvantages of delivery methods from the perspective of Iranian primiparous women $(\mathrm{n}=460)$

\begin{tabular}{|c|c|c|c|}
\hline & \multicolumn{2}{|l|}{ Delivery method } \\
\hline & & C-section & Vaginal delivery \\
\hline \multirow[t]{2}{*}{ Advantages } & Group A & - $\quad$ Less pain during delivery & $\begin{array}{ll}\text { - } & \text { Fast recovery } \\
\text { - } & \text { Safety } \\
\text { - } & \text { Less Bleeding } \\
\text { - } & \text { No need for anesthesia }\end{array}$ \\
\hline & Group B & - Less pain during delivery & $\begin{array}{ll}\text { - } & \text { Low cost } \\
\text { - } & \text { Fast recovery }\end{array}$ \\
\hline \multirow[t]{2}{*}{ Disadvantages } & Group A & $\begin{array}{l}\text { - side effects of the anesthesia and fear of } \\
\text { it } \\
\text { - Delayed recovery }\end{array}$ & $\begin{array}{l}\text { - Severe pain in } \\
\text { delivery }\end{array}$ \\
\hline & Group B & $\begin{array}{ll}\text { - } & \text { Bleeding } \\
\text { - } & \text { Pain of suture places }\end{array}$ & $\begin{array}{l}\text { - Severe pain in } \\
\text { delivery } \\
\text { - } \quad \text { Perineal damage }\end{array}$ \\
\hline
\end{tabular}

Group A: participants who had C-section; Group B: participants who had vaginal delivery

\section{Discussion}

Findings of this study showed that level of education, income and the social class, opinions and tendency of the husband, physician's opinion, recommendations of family/friends, fear and lack of information, maternal care during the pregnancy, previous experience about delivery, and the perception of them on advantages and disadvantages of each delivery method were factors that had influence in choosing the delivery method. This study revealed that employment status of the women had no significant impact on choosing the delivery method. This finding is in line with the studies of Mohammadpour et al. in Maragheh city (19), Zamani Alavijeh et al. in Ahwaz city (20), Sharghi et al. in Ardabil city (21), and other similar studies conducted in Iran. The possible reason for this finding may be the culture of Iranian people that assumes no responsibility of family expenditure for the wives. The other finding that the more educated the women, the higher rate of $\mathrm{C}$-section, is in line with the study of Alimohammadian et al. in Tehran (22) and Murray et al. in Chile (7). It seems that it is, beyond to increased information, due to the low pain of the $\mathrm{C}$-section and the perception of $\mathrm{C}$-section as a luxury. Another important finding was that the tendency to $\mathrm{C}$ - 
section increases by increasing the family income. This is similar to the findings of the study of Behague in Brazil (23) and Mohammadi Tabar et al. in Tehran (8). This study also indicated that the rate of C-section in those women who had received maternal care from physicians of the private sector and the specialist physician was higher. Shareat et al. (24) showed that $84 \%$ of the cases that had received maternal care from private physicians lead to Csection while the rate for public sector caregivers is $47 \%$. Also, $50 \%$ of the participants of this study stated the insistence of the physician as the main reason for choosing to have $\mathrm{C}$-section. This shows the key role of physicians and generally the healthcare workers in the individual's decisions. Faraji et al. showed that the physician had the main role in choosing C-section in $70 \%$ of the cases (25). Signorelli et al., in a study in Italy, (26) found the caregiver physician to have the main role in choosing the delivery method. It seems that the judgment of the physician about the situation is more influencing than the real situation. Menacker et al. stated that the tendency and judgment of the physicians was the reason for the growing rate of $\mathrm{C}$-section among those mothers who had no indication for it (27). A potential cause for this tendency of physicians to C-section may be that C-section, compared to vaginal delivery, consumes less time and effort and produces more profit for them. On the other hand, this study showed that the knowledge of the mothers about the delivery methods was poor. Participants of this study had little information about the delivery methods and their consequences. This low information leads to more influence of recommendations of physicians and others. Knowledge is one of the influential factors in healthcare seeking behavior, and choosing the delivery method, like other health-related decisions, is affected by the individual's knowledge. Anderson (28) states that to decrease the un-necessary C-section rate and to increase the vaginal delivery, the knowledge of women should be improved. Graham et al. (29), in another study, reported that the knowledge of mothers about the delivery methods is limited and their information needs are different. Yet the information should be provided to them by healthcare workers. Thus, we recommend that effective plans for education of pregnant women by healthcare providers be implemented and monitored to elevate the situation. The other influential factor examined in this study was the perspective of primiparous women about the advantages and disadvantages of each delivery method. The participants stated less pain as the main advantage of $\mathrm{C}$-section, and the safety, fast recovery and less side effects as the advantages of vaginal delivery. In the study of Alavijeh et al. (20) about $81 \%$, and in the study of Arjmandi et al. about $71 \%$ of women were aware of fast recovery after vaginal delivery and perceived it as the main advantage of this delivery method. Regarding the fact that most of the women are aware of the advantages of vaginal delivery, if we want to promote this method, we should simply counter its main disadvantage which is severe pain. The pain can be resolved by various clinical procedures.

\section{Conclusions}

Social factors and motivation to obey abstract norms, especially opinions of physicians and healthcare workers, have influences on the final intention to do health-related behaviors. Considering such social factors, we can enforce the intention of mothers to have vaginal delivery by improving their knowledge and perception of this delivery method. They should also have support to do so. Mothers should be informed that if there is no contra-indication for vaginal delivery, it is notably safer and has fewer side effects than a large invasive operation such as cesarean section.

\section{Acknowledgments:}

The authors are sincerely grateful for all participants in the study. We are also immensely grateful to Kalil Kallavani for comments on an earlier version of the manuscript.

\section{Conflict of Interest:}

There is no conflict of interest to be declared.

\section{Authors' contributions:}

All authors contributed to this project and article equally. All authors read and approved the final manuscript.

\section{References:}

1) David H, Norman J. Gynecology illustrated. 5, editor. London: Churchill Livingstone Co; 2000.

2) Malcolm S, Ian M. Essential obstetrics and Gynecology. edition T, editor: Churchill LivingstoneCo; 1998.

3) Cunningham F, Leveno K, Bloom S, Fauser J, Zwirner M. Williams Obstetrics. 22, editor. New York: Graw-Hill; 2005.

4) Betran AP, Merialdi M, Lauer JA, Bing-Shun W, Thomas J, Van Look P, et al. Rates of caesarean section: analysis of global, regional and national estimates. Paediatr Perinat Epidemiol. 2007;21(2):98-113. PMID: 17302638, DOI: $10.1111 / \mathrm{j} .1365-3016.2007 .00786 . x$ 
5) Hart D, Norman J, Callander R, Govan A. Gynaecology illustrated. 5th, editor. London: Churchill Livingstone; 2000.

6) Hopkins K. Are Brazilian women really choosing to deliver by Cesarean. Soc Sci Med. 2000;51(5):725-40. DOI: 10.1016/S0277-9536(99)00480-3, PMID: 10975232

7) Murray S. Relation between private health insurance and high rates of caesarean section in Chile: qualitative and quantitative study. BMJ. 2000;321(7275):1501-5. PMID: 11118176, PMCID: PMC27552

8) Mohammaditabar S, Kiani A, Heydari M. The survey on tendencies of primiparous women for selecting the mode of delivery. J Babol Univ Med Sci. 2009;11(50):54-9.

9) Torkzahrani S. Commentary: childbirth education in Iran. J Perinat Educ. 2008;17(3):51-4. PMID: 19436412, PMCID: PMC2517184 DOI: 10.1624/105812408X329601

10) shareferad G, fathean $Z$, Terane M, Mahake B. The Survey of pregnant women views about delivery and cesarian According Behavioral intention model. Elam Uni Med Sc J. 2007;15(1):19-23.

11) Azami-aghdash S, Ghojazadeh M, Dehdilani N, Mohammadi M, Asl amin abad R. Prevalence and Causes of Cesarean Section in Iran: Systematic Review and Meta-Analysis. Iranian J Publ Health. 2014;43(5):54555. PMID: 26060756, PMCID: PMC4449402

12) Ananth CV, Vintzileos AM. Trends in cesarean delivery at preterm gestation and association with perinatal mortality. Am J Obstet Gynecol. 2011;204(6):31. PMID: 21457916, DOI: 10.1016/j.ajog.2011.01.062

13) Cheng YW, Eden KB, Marshall N, Pereira L, Caughey AB, Guise JM. Delivery after prior cesarean: maternal morbidity and mortality. Clin Perinatol. 2011;38(2):297-309. PMID: 21645797, PMCID: PMC3428794 DOI: 10.1016/j.clp.2011.03.012

14) Huang X, Lei J, Tan H, Walker M, Zhou J, Wen SW. Cesarean delivery for first pregnancy and neonatal morbidity and mortality in second pregnancy. Eur J Obstet Gynecol Reprod Biol. 2011;158(2):204-8. PMID: 21641102, DOI: 10.1016/j.ejogrb.2011.05.006

15) Cunningham F. Williams Obstetrics. 22, editor: Golban Publications; 2005.

16) Arjmandi B, Farzin M. Assessment of the Level of the Pregnant Womens Knowledge Towards the Advantages and Disadvantages of Normal Vaginal Delivery and Cesarean Section, Tehran(2005). J Iran Univ Medl Sci. 2007;14(55).

17) Monari F, Mario S, Facchinetti F, Basevi V. Obstetricians' and midwives' attitudes toward cesarean section. Birth. 2008;35(2):129-35. PMID: 18507584, DOI: 10.1111/j.1523-536X.2008.00226.x

18) Bahrie M, Latifnejad R, Abdollahian E, Esmaili H. Effect of midwife's psycologiy \& physical \& Educational supportive in duration of labor stages and lobor pain force. J Sabzevar Univ Medl Sci 2004;11(1):23-4.

19) Asghar M, Parivash A, Fatemeh R, Arezoo A, Hossein A. Investigating the Choice of Delivery Method Type and Its Related Factors in Pregnant Women in Maragheh. Knowledge \& Health. 2009;4(1):36-9.

20) Alavije Z, Shahry P, Kalhory M, Haghighizadeh M, Sharifirad G, Khorsandi M. Identification of factors related to elective cesarean labor: a theory-based study. Daneshvar (medicine) Shahed University. 2012;96:1-11.

21) Sharghi A, Kamran A, Sharifirad G. Factors Influencing Delivery Method Selection in Primiparous Pregnant Women Referred to Health Centers in Ardabil, Iran. J Health Syst Res. 2011;7(3):364-72.

22) Alimohamadian M, Shariat M, Mahmoodi M, Ramezanzadeh F. The survey of impact of pregnant women's request in selected cesarean. Payesh. 2003;2:133-9.

23) Behague D, Victora C, Barros F. Consumer demand for caesarean sections in Brazil: informed decision making, patient choice, or social inequality? A population based birth cohort study linking ethnographic and epidemiological methods. BMJ. 2002;324(7343):942-5. PMID: 11964338, PMCID: PMC102326

24) SHareat M, Majlasei F, Azarei S, Mahmodei M. Cesarean section rate and its determinants in maternity hospitals in Tehran. Payesh. 2002;1(3):5-10.

25) Faraji Dor Khaneh R, Zahiri S, Farjad B. Knowledge and Attitudes of pregnant women to normal delivery methods. J Guilan Univ Med Sci. 2003;12(46):69-75.

26) Signorelli C, Cattaruzza M, Osborn J. Risk factors for caesarean section in Italy: results of a multicentre study. Public Health. 1995;109(3):191-9. DOI: 10.1016/S0033-3506(05)80052-6, PMID: 7597132

27) Menacker F, Declercq E, Mac M. Cesarean delivery: background, trends, and epidemiology. Semin Perinatol. 2006;30(5):235-41. PMID: 17011392, DOI: 10.1053/j.semperi.2006.07.002

28) Anderson E. Health and disease prevention. Nursing Outlook. 1996;10(5):1105-252.

29) Graham W, Hundley V, McCheyne A, Hall M, Gurney E, Milne J. An investigation of women's involvement in the decision to deliver by caesarean section. Br J Obstet Gynaecol. 1999;106(3):213-20. PMID: 10426639 